\title{
The Prevalence of Psychosomatic Symptoms and Spirituality Levels among University Students in South Jordan
}

\author{
Hani A. Nawafleh*, Lourance A. Al Hadid, Muwafaq M. Al Momani, Ahmad M. Al Sayeh \\ Princess Aisha Bint Al Hussein College of Nursing and Health Sciences, Al Hussein Bin Talal University, Ma'an, Jordan \\ Email: ^hnawafleh@ahu.edu.jo, Hadid.1@ahu.edu.jo, M.Al-Momani@ahu.edu.jo, a.sayeh@ahu.edu.jo
}

How to cite this paper: Nawafleh, H.A., Al Hadid, L.A., Al Momani, M.M. and Al Sayeh, A.M. (2018) The Prevalence of Psychosomatic Symptoms and Spirituality Levels among University Students in South Jordan. Health, 10, 107-121.

https://doi.org/10.4236/health.2018.101009

Received: December 24, 2017

Accepted: January 22, 2018

Published: January 25, 2018

Copyright ( 92018 by authors and Scientific Research Publishing Inc. This work is licensed under the Creative Commons Attribution International License (CC BY 4.0).

http://creativecommons.org/licenses/by/4.0/

\begin{abstract}
Psychosomatic symptoms are present in various stages of life. University students have also manifested such symptoms, which were also found to be linked to the level of spirituality affecting physical and psychological well-being. This study aims to examine whether spirituality can predict the presence of psychosomatic symptoms by investigating the relationship between the prevalence of psychosomatic symptoms and the level of spirituality among university students in South Jordan. An exploratory cross-sectional design involving convenience samples and self-administered questionnaires using the twelve-item general health questionnaire including spirituality-based items were used to collect data for this study. A total of 1269 completed the study questionnaire. Students' responses indicated various psychosomatic symptoms causing issues to better academic achievement, including students' feeling of uselessness, followed by their lack of happiness, inability to make decisions and solve problems, and lack of concentration on what they are doing. They considered spirituality as an important part of their life. Lower scores on general health questionnaire were observed to have higher scores on spirituality items indicating that students with better spirituality practices have less psychological symptoms. Based on the findings of this study, the level of spirituality influences the prevalence of psychosomatic symptoms. Conducting educational programs to improve the spiritual well-being of students could be beneficial. Further, it is important that students' affairs board at the university perform proper assessment and interventions to improve the spirituality level to decrease the impact of psychosomatic symptoms among students.
\end{abstract}

\section{Keywords}

Spirituality, Mental Health, Students, Psychosomatic, Jordan 


\section{Introduction}

Psychosomatic symptoms are present in various stages of human life [1] [2] [3]. Studies cited that approximately $50 \%$ of adolescents aged 14 years are already diagnosed with psychosomatic symptoms. This proportion might increase to $75 \%$ by age of 24 years. Majority of university students are within this age range of 14 - 24 years [4]. Psychosomatic symptoms influence how a person behaves, perceives and reacts to the surrounding world [5]. These symptoms affect students who are vulnerable to different negative effects associated with the presence of such symptoms, including but not limited to academic achievement, illicit drug use, and suicidal intention [1]. Students usually experience stress due to study obligations, family and peer pressures, and other causes [6] [7] [8]. As these psychosomatic symptoms mostly appear in the early adulthood period, they could be detected and managed in the early stages of the disease [3] [4]. Some factors that could influence the severity of the psychosomatic symptoms, include level of spirituality and support from the academic institution [9]. Evidences based on literature indicate that the prevalence of mental health status among students is influenced by spirituality [9] [10] [11] [12].

Spirituality was defined as "the intrinsic human capacity for self-transcendence, in which the self is embedded in something greater than the self, including the sacred". It motivates "the search for connectedness, meaning, purpose, and contribution" [10] [13]. It was also perceived as the subjective, mystical, and holistic interpretation of personal beliefs and behaviours [14]. Mental health nurses and other health professionals generally recognise spirituality as a set of experiences and feelings associated with personal knowledge, meaning, hope, connectedness, transcendence, love, and compassion, as well as, a connection to something blessed [15]. Furthermore, complexities in life like place of origin, family income, family type, university environment, perceived parent, teacher, and classmate support were all significant factors for spiritual belief [16]

Yamashita et al. [17] reported three coping styles as stress management strategies to address psychosomatic symptoms, e.g., active coping, avoiding self-blame, and acceptance and behavioural disengagement. In year 2000, a study among 261 oncology attendees, house staff, and nurses showed that religion and spirituality were also associated with lower levels of exhaustion and stress [18]. While on the other hand, students who achieved higher scores on spirituality measures were less likely to have depression or burnout. Therefore, one might say that better spiritual experiences are associated with higher life satisfaction and lower psychological distress and burnout. In an earlier study of 80 palliative care mental and medical health care workers, spirituality was essential to alleviate cognitive, emotional, and physical symptoms of burnout [19]. Similarly, a study of Vasegh and Mohammadi [20] in Iran assessed the associations between religious variables, anxiety, and depression in a sample of Muslim students also found that religious activities might control and alleviate depression and anxiety.

Religiosity as part of spirituality was considered a salient component and a 
contributing factor to quality of life. Such was recommended to be integrated in the psychotherapeutic procedures among college students [21] [22]. This finding was also seen in two studies which were conducted in different cultures in $\mathrm{Ku}$ wait. Abdel-Khalek [23] studied adolescents, middle-aged population, and college students. He found out that religiosity was a principal factor for happiness and mental health in all age groups included in the study. Wachholtz and Rogoff [24] in the USA found that spiritual wellbeing and daily spiritual exercises significantly influence the psychological status and decrease rate of burnout among medical students. Another study in Australia included 483 undergraduate students and found that psychological status was also associated with religiosity and personal beliefs [25]. Various studies were conducted to uncover psychological symptoms among students in Jordan [26] [27] [28]. However, little or none has ever been conducted in the South of Jordan that focused on psychological symptoms in association with spirituality of students. Therefore, this study aims to investigate the relationship between the prevalence of psychosomatic symptoms and the level of spirituality among university students in the South of Jordan. On one hand, it seeks to examine whether spirituality can predict the prevalence of psychosomatic symptoms.

\section{Methods}

\subsection{Design}

An exploratory cross-sectional design targeting convenience sample and self-report field survey questionnaire were used to gather data for the study.

\subsection{Study Settings}

The authors of the study approached universities and colleges in the South of Jordan which are affiliated with the Ministry of Higher Education and Research. These are Al-Hussein Bin Talal University, Tafeeleh University, Mu'tah University, south colleges that belong to Balqa' University (e.g., Ma'an College, Shoubak College, Aqaba College), and the University of Jordan-Aqaba.

Ethical approval was sought from Al-Hussein Bin Talal University Research Ethics Committee to comply with the local ethical rules and regulations within each of the individual study sites. A self-administered questionnaire pack was provided to the students to obtain information. Completed questionnaires were submitted to the Dean's Office in each of the selected sites. The information pack included the cover letter, information sheet, copy of the questionnaire, and return stamped envelope for the completed questionnaire. Reminder letters were dispatched two weeks after the questionnaire packs were given to students who have not yet sent their replies in order to maximize the response rate.

\subsection{Instrument}

A structured questionnaire used for this study focused on eliciting views and beliefs of university students on their spiritual and psychosomatic symptoms. Part 
one captures the demographic details of the participants such as: age, gender, religion, and academic year. Part two comprises the twelve-point General Health Questionnaire (GHQ-12) [29] that measures the psychosomatic symptoms among healthy people. The third part dwells on the Spirituality Questionnaire [30].

The GHQ-12 was originally developed in the United Kingdom and was one of the most widely used screening questionnaire to detect common mental health, as well as, the severity of psychological distress including symptoms of anxiety and depressive disorders among individuals [31]. It consists of 12 items with a 4-point Likert Scale, which is transformed when reporting into a bi-modal scoring $(0-1)$ with higher scores indicating more psychological symptoms [29]. It consists of three underlying factors: psychological distress; social and emotional dysfunction; and cognitive disorder.

The spirituality questionnaire was developed and validated by Parsian and Dunning [30], who granted the approval to use it in this study. It consists of 29 items measured through the 4-point Likert's scale ranges of which are as follow: (1) strongly disagree; (2) disagree; (3) agree; and, (4) strongly agree with the total score ranging from 29 to 116 in which higher scores indicate better spirituality [30]. This measures four (4) dimensions of spirituality, namely: self-awareness; importance of spiritual beliefs in life; spiritual practices; and, spiritual needs.

Self-awareness reflects how students view themselves. The importance of spiritual beliefs in life was measured by the students' opinions about their own spiritual beliefs in their life. Spiritual practice focuses on the spiritual experience. While, the dimension of spiritual needs focus on what students looks for and try to achieve to meet their needs. The sum of scores on these dimensions reflects the spirituality status of the individual. It encompasses the following concepts: finding meaning in life; self-actualization; and connection with the inner self and the universe as a whole [30].

The spirituality questionnaire was translated to Arabic and 21 items were validated based on the four subscales: self-awareness (6 items), importance of spirituality in life (5 items), spiritual practice (6 items), and spiritual needs (4 items) [30]. The questionnaire was translated from English to Arabic language and back to English by independent bilingual translators without accessing the original version. Any discrepancy in the meaning between the original version and retranslation from Arabic to English were considered and reviewed intensively to achieve congruent meanings.

\subsection{Participants and Recruitment}

The sample included all students at all levels enrolled in all study sites that were available during the orientation period. There were no restrictions with respect to demographic characteristics such as age, gender, religion, and the type of study or specialization. All participants should be free from any known physical or psychological condition.

Coordination with the deanship of students' affairs, deans of the universities 
and colleges were established to facilitate the dissemination of the questionnaires to their students. Deans were sent letters to seek their approval for the researcher to approach and orient the students to participate in the study. Student samples were provided with copies of all the study documents, as well as, a copy of the local ethical board approval. There were 2,496 students eligible and were available at the time of the study.

\subsection{Data Analysis}

Data were encoded and analysed using the SPSS * 21 software which enabled clearing and filtering any outliers or any missing data. Categorical and continuous data were presented as frequencies, percentages, distribution of means, and standard deviations to provide an overview of the students' demography. Categorical data, including demographic variables, as well as, questions with categorical responses (Yes/No), were cross-tabulated and presented in tables and graphs, as appropriate. Comparisons between universities were analysed using chi-square test. Continuous data were presented by means and standard deviation. Both categorical and continuous data from students' responses were explored and compared using suitable statistical tests.

\section{Findings}

\subsection{Participants' Characteristics}

A total of two thousand four hundred ninety-six (2496) students were oriented but only 1269 completed the study questionnaire, hence, a response rate of $51 \%$. The mean age of participants was 21.41 years, ranging between 18 - 49 years of age. More than half of the participants were females $(n=700,55.2 \%)$ and the majority ( $\mathrm{n}=1125,88.7 \%$ ) were single, with $109(8.6 \%)$ married. Regarding specialization or courses studied, $629(49.4 \%)$ were enrolled in applied sciences, 502 (39.6\%) were in social sciences, and $140(5.6 \%)$ were in natural and health sciences. Most students $(\mathrm{n}=236,97.4 \%)$ were enrolled in Bachelor programs, 22 $(1.7 \%)$ in masters, and $11(0.9 \%)$ were in doctorate degree. Most of the participants were in years 1,2 , and 3 with only 41 students $(3.2 \%)$ were from the fifth year with less than $0.7 \%$ in the 6 th year. Table 1 shows details of the demographic characteristics of participants.

\subsection{Psychosomatic Symptoms and Mental Health}

Each individual item of the GHQ-12 was considered as students' barrier towards better academic achievement. Table 2 shows the frequency of scores on these items rated with $0=$ agree and $1=$ disagree. The highest barrier considered by students was their feeling of not playing a useful part in things (78.8\%). The second higher barrier was lack of happiness $(77.6 \%)$. The third barrier was the students' inability to make their own decisions (77.1\%). The fourth barrier was their inability to solve problems (76.2\%). The fifth barrier was students' inability to concentrate on what they are doing $(75.9 \%)$. 
Table 1. Demographic characteristics of participants*.

\begin{tabular}{|c|c|c|c|c|}
\hline \multicolumn{2}{|c|}{ Group } & \multirow[b]{2}{*}{569} & \multirow[b]{2}{*}{$44.8 \%$} & \multirow[b]{2}{*}{0.019} \\
\hline Gender & Male & & & \\
\hline & Female & 700 & $55.2 \%$ & \\
\hline \multirow[t]{4}{*}{ Marital Status } & Married & 109 & $8.6 \%$ & 0.000 \\
\hline & Single & 1125 & $88.7 \%$ & \\
\hline & Divorced & 20 & $1.6 \%$ & \\
\hline & Widowed & 15 & $1.2 \%$ & \\
\hline \multirow[t]{4}{*}{ Specialization } & Social sciences & 502 & $39.6 \%$ & 0.320 \\
\hline & Natural sciences & 52 & $4.1 \%$ & \\
\hline & Health sciences & 88 & $6.9 \%$ & \\
\hline & Applied sciences & 629 & $49.4 \%$ & \\
\hline \multirow[t]{3}{*}{ Residence } & Live alone & 145 & $11.4 \%$ & 0.000 \\
\hline & Live with roommates & 464 & $36.6 \%$ & \\
\hline & Live with family & 660 & $52 \%$ & \\
\hline \multirow[t]{3}{*}{ Education } & Bachelor & 1,236 & $97.4 \%$ & \\
\hline & Master & 22 & $1.7 \%$ & \\
\hline & Doctorate & 11 & $0.9 \%$ & \\
\hline \multirow[t]{6}{*}{ Year of Education } & First year & 345 & $27.2 \%$ & 0.001 \\
\hline & Second year & 273 & $21.5 \%$ & \\
\hline & Third year & 305 & $24 \%$ & \\
\hline & Fourth year & 298 & 23.5 & \\
\hline & Fifth year & 41 & $3.2 \%$ & \\
\hline & Sixth year & 7 & $<0.6$ & \\
\hline \multirow[t]{4}{*}{ Student's average in the course } & Fair & 321 & $25.3 \%$ & 0.0560 \\
\hline & Good & 564 & $44.4 \%$ & \\
\hline & Very good & 279 & $22 \%$ & \\
\hline & Excellent & 105 & $8.3 \%$ & \\
\hline \multirow[t]{4}{*}{ Source of funding } & Scholarship & 563 & $44.4 \%$ & 0.5420 \\
\hline & Self-supported & 584 & $46 \%$ & \\
\hline & Parallel track & 119 & $9.4 \%$ & \\
\hline & International students & 3 & $0.2 \%$ & \\
\hline
\end{tabular}

*None of the student had any physical or psychological problem at the time of data collection.

Table 2. Frequency distribution of scores on GHQ-12.

\begin{tabular}{|c|c|c|}
\hline & \multicolumn{2}{|c|}{ Frequency of Score (\% compared to total scores) } \\
\hline & $0^{*}$ & $1^{*}$ \\
\hline Have you been able to concentrate on whatever you are doing? & $895(70.5)$ & $374(29.5)$ \\
\hline Have you lost much sleep over worry? & $646(50.9)$ & $623(50.1)$ \\
\hline Have you felt that you were playing a useful part in things? & $998(78.8)$ & $271(21.3)$ \\
\hline Have you felt capable of making decisions about things? & $964(75.9)$ & $305(24.1)$ \\
\hline Have you felt constantly under strain? & $663(52.3)$ & $606(47.8)$ \\
\hline Have you felt that you could not overcome your difficulties? & $860(58.1)$ & $409(32.2)$ \\
\hline Have you been able to enjoy your normal day-to-day activities? & $811(63.9)$ & $458(36.1)$ \\
\hline Have you been able to face up to your problems? & $912(71.9)$ & $357(28.2)$ \\
\hline Have you been feeling unhappy and depressed? & $803(63.3)$ & $466(36.7)$ \\
\hline Have you been losing confidence in yourself? & $966(76.2)$ & $303(23.8)$ \\
\hline Have you been thinking of yourself as a worthless person? & $979(77.1)$ & $290(22.8)$ \\
\hline Have you been feeling reasonably happy, all things considered? & 985 (77.6) & $284(22.4)$ \\
\hline
\end{tabular}

*Responses were either 0 (+/agree) or 1 (-/disagree). 
Table 3 shows a description of the GHQ-12 items with a mean of 3.74, SD = 2.57 indicating less mental health and psychiatric symptoms among students. However, students' responses with high scores reflected more psychosomatic symptoms, such as: "Have you lost much sleep over worry?" (0.49); "Have you felt that you were playing a useful part in things?" (0.48); and, "Have you felt constantly under strain?" (0.45).

Students' scores on mental health scale (refer to Table 1) differed significantly with students' gender $(\mathrm{p}=0.019)$, residence $(\mathrm{p}<0.001)$, marital status $(\mathrm{p}<$ $0.001)$, and academic year $(\mathrm{p}=0.001)$. There was no significant difference among students from different areas of study (specialization) $(\mathrm{p}=0.320)$.

\subsection{Students' Perspectives on Their Spirituality}

Generally, students showed positive feeling on spirituality items with the mean score on the overall questionnaire at $59.95, \mathrm{SD}=12.5$. The average scores in its subscales: self-awareness, $28.9, \mathrm{SD}=7$; importance of spiritual belief in life, 11.4, $\mathrm{SD}=2.95$; spiritual practice, $16, \mathrm{SD}=4$; and, spiritual needs $26.1, \mathrm{SD}=5.8$, respectively (refer to Table 4).

Table 3. Descriptions for individual items of GHQ-12.

\begin{tabular}{lcccc}
\hline \multicolumn{1}{c}{ Item } & Mean & SD & Skewness (SE) & Kurtosis (SE) \\
\hline Overall GHQ score & 3.74 & 2.57 & $0.902(0.069)$ & $-1.189-(0.137)$ \\
Have you been able to concentrate on whatever you are doing? & 0.3 & 0.46 & $0.036(0.069)$ & $-2.450-(0.137)$ \\
Have you lost much sleep over worry? & 0.49 & 0.50 & $-1.423-(0.137)$ & 0.713 \\
Have you felt that you were playing a useful part in things? & 0.48 & 0.47 & $0.580(0.069)$ & $-1.423-(0.137)$ \\
Have you felt capable of making decisions about things? & 0.21 & 0.48 & $0.974(0.069)$ & $-1.346-(0.137)$ \\
Have you felt constantly under strain? & 0.45 & 0.24 & $0.552(0.069)$ & $-1.053-(0.137)$ \\
Have you felt that you could not overcome your difficulties? & 0.36 & 0.48 & $1.227(0.069)$ & $-1.298-(0.137)$ \\
Have you been able to enjoy your normal day-to-day activities? & 0.28 & 0.43 & $1.295(0.069)$ & $-0.495-(0.137)$ \\
Have you been able to face up to your problems? & 0.37 & 0.42 & $1.327(0.069)$ & $-0.324-(0.137)$ \\
Have you been feeling unhappy and depressed? & 0.24 & 0.48 & $0.580(0.069)$ & $-0.240-(0.137)$ \\
Have you been losing confidence in yourself? & 0.23 & 0.50 & $0.090(0.069)$ & $-1.395-(0.137)$ \\
Have you been thinking of yourself as a worthless person? & 0.22 & 0.41 & $1.400(0.069)$ & $-0.041-(0.137)$ \\
Have you been feeling reasonably happy, all things considered? & 0.361 & 0.428 & $1.217(0.069)$ & $-0.520-(0.137)$ \\
\hline
\end{tabular}

Table 4. Descriptions for individual items on the Spirituality Questionnaire.

\begin{tabular}{lcccc}
\hline \multicolumn{1}{c}{ Item } & Min & Max & Mean & SD \\
\hline Overall student perspective & 21 & 118 & 59.95 & 12.5 \\
Self-awareness & 10 & 78 & 28.9 & 7 \\
Importance of spiritual beliefs in life & 4 & 16 & 11.4 & 2.95 \\
Spiritual practices & 6 & 58 & 16 & 4 \\
Spiritual needs & 9 & 36 & 26.1 & 5.8 \\
\hline
\end{tabular}


Spirituality mean scores were significantly different among participants from several types of residences ( $\mathrm{p}<0.001)$, marital status $(\mathrm{p}<0.001)$, specialization $(\mathrm{p}<0.001)$, and academic degree $(\mathrm{p}=0.028)$. No significant difference was found among participants based on gender $(\mathrm{p}=0.123)$.

Accordingly, students were more aware of themselves and their purpose and meaning of life. They also considered spirituality as an important issue in their life. Students' responses indicated that they practice spirituality regularly and need to be engaged in more spiritual activities. Students' responses on all items indicated high spirituality on five highest items, namely: (1) "I believe I am equal to other people (76.3\%); (2) "I am satisfied with who I am" (74.8\%); (3) "I search for a purpose in life" (74.1\%); (4) "I have positive attitude towards myself" (73\%); and, (5) "I seek beauty in my life" (73\%) (Table 5).

Table 5. Participants' responses on the individual items.

\begin{tabular}{|c|c|c|c|}
\hline & Item & $0^{*}(\%)$ & $1^{\star}(\%)$ \\
\hline \multicolumn{4}{|c|}{ Self-awareness } \\
\hline 1 & I am satisfied with who I am. & $320(25.2)$ & $940(74.8)$ \\
\hline 2 & I have good qualities. & $448(35.3)$ & $821(64.7)$ \\
\hline 3 & I have positive attitude towards myself. & $342(27)$ & $927(73)$ \\
\hline 4 & I am a worthy person. & $349(27.5)$ & $920(72.5)$ \\
\hline 7 & I believe I am equal to other people. & $301(23.7)$ & $968(76.3)$ \\
\hline 8 & I am a compassionate person. & $356(28.1)$ & $913(71.9)$ \\
\hline \multicolumn{4}{|c|}{ Importance of spiritual beliefs in life } \\
\hline 9 & I find meaning in difficult situations. & $406(32)$ & $863(68)$ \\
\hline 10 & I think about positive things. & $407(32.5)$ & $861(67.9)$ \\
\hline 11 & My spirituality helps me define my goals. & $413(32.5)$ & $856(67.5)$ \\
\hline 13 & My spirituality is part of my whole approach to life. & $381(30)$ & $888(70)$ \\
\hline 14 & My spirituality is integrated into my life. & $423(33.3)$ & $846(66.7)$ \\
\hline \multicolumn{4}{|c|}{ Spiritual practice } \\
\hline 17 & I meditate to achieve inner peace. & $410(32.3)$ & $859(67.7)$ \\
\hline 18 & I try to live in harmony with nature. & $368(28.9)$ & $901(71.1)$ \\
\hline 19 & I try to find any opportunity to enhance spirituality. & $643(50.6)$ & $626(49.4)$ \\
\hline 21 & I search for a purpose in life. & $329(25.9)$ & $940(74.1)$ \\
\hline 22 & I enjoy listening to music. & $369(29.1)$ & $900(70.9)$ \\
\hline 23 & I need to find answers to the life mysteries. & $361(28.4)$ & $908(71.6)$ \\
\hline \multicolumn{4}{|c|}{ Spiritual needs } \\
\hline 26 & I seek beauty in my life. & $343(27)$ & $926(73)$ \\
\hline 27 & I need to have strong connections with people. & $397(31.3)$ & $872(68.7)$ \\
\hline 28 & My life is evolving. & $346(27.3)$ & $923(72.7)$ \\
\hline 29 & I need to develop a meaningful life. & $363(28.6)$ & $906(71.4)$ \\
\hline
\end{tabular}

*Responses were either 0 (+/agree) or 1 (-/disagree). 


\subsection{Spirituality and Mental Health}

Students' scores on the GHQ-12 correlated negatively with the spirituality conditions of students $(r=-0.33)$. Lower scores on GHQ were noticed with higher scores on spirituality, indicating that better spirituality of students was observed in students with less psychological symptoms. In the same way, GHQ-12 mean scores were also negative and significantly correlated with all spirituality subscales: self-awareness $(r=-0.377, \mathrm{p}<0.001)$; importance of spiritual beliefs $(r=$ $-0.277, \mathrm{p}<0.001)$; spiritual practice $(r=-0.195, \mathrm{p}<0.001)$; and spiritual needs $(r=-0.207, \mathrm{p}<0.001)$.

\subsection{Linear Regression}

Multiple linear regression was calculated to predict GHQ total mean score (dependent variable) based on the spirituality questionnaire (SQ) mean scores (independent variable). A significant regression equation was found $[F(1,1267)=$ 153.910, $\mathrm{p}<0.001$ ] with an R2 of 0.142 .

Participants' predicted the psychosomatic symptoms score (measured by GHQ-12 mean score) as equal to 7.796; while the spirituality mean score is -0.068 . Participants' GHQ-12 mean scores decreased by 0.068 for each score on the GHQ-12. Based on findings in this study, SQ mean score is a significant predictor to GHQ-12 mean score.

\section{Discussion}

Students in the current study reported experiencing different psychological symptoms related to social dysfunction, anxiety, and depression. They felt unhappy and could not enjoy things they want to do in their lives. Students were also unable to make their own decisions and solve their problems. They also reported difficulty concentrating on what they do. Less common symptoms reported by students in this study included loss of sleep and feeling strained as they perform simple everyday things, such as, reading and discussing problems with colleagues. Similar findings were also found in a variety of studies from different countries [2] [32]. Although psychological symptoms were found among university students, [2] [3] other studies emphasized that these symptoms are more likely to begin at earlier ages, such as at the age of 14 , and then increases as students join the university.

Based on findings in this study, students reported having difficulty when trying to make decisions or stay focused when thinking. These psychological symptoms influenced their ability to concentrate, consequently affecting their academic achievement. This was clearly evident in other studies where students exhibited behaviour and reactions that were inappropriate due to the presence of these symptoms [5]. In addition, these symptoms were associated with suicidal intents when unrecognized or not properly addressed [1]. This indeed may expand the risk of academic failure to social fallout and widen the circle of the 
problem, which need further efforts to be resolved.

Early management of the problem in this adulthood stage was found to be easier and need fewer resources. Recently, Weich et al. [4] and Lindström et al., [3] emphasized that psychosomatic symptoms were most likely to appear in the early adulthood. The other force that could help manage the problem in the current study was the students' high level of confidence and feeling of worthiness even if they felt unhappy, unable to enjoy activities, and face problems. Further, students were keen on finding solutions to improve their role in the society, as indicated in their response on "not playing a useful part in things." In this regard, one might say that findings of this study have remarkable implication in the future.

Findings in this study indicated the prevalence of psychological symptoms, which might advertently influence the students' present and future life. This indicates that there is a need to assess the presence of such symptoms among all university students by using well-established guidelines. A study showed that little or no evidence was generated about seeking consultation or help from nurses or other healthcare professionals, as well as, specialists in the psychiatric field [33]. A more recent review came out with the emerging evidence on using guidelines for the assessment of psychiatric symptoms [34]. These guidelines include a process of identification of psychiatric symptoms, behavioural equivalents, diagnostic criteria, setting, sources of information, screening, and diagnostic tools.

In this study, spirituality was found to be a predictor of the psychological status. High spirituality level was associated with less psychological and mental health symptoms $(\mathrm{F}=153.9, \mathrm{p}<0.001)$. Specifically, when students experience high spiritual levels and show positive attitude towards others they find meaning for their life and feel the need to have stronger connections with other people, thus, creating better confidence and mental health [11] [35]. There were also reports that higher levels of spirituality were associated with better coping strategies to problems and stress. Similarly, Vergehese [10] reported that religious practices and spirituality levels were associated with lower levels of exhaustion and stress among healthy populations [10] [18]. In Kash et al. study, [18] students who achieved higher scores on spirituality measures were less likely to have depression or endorse items correlated with high burnout. Powell et al., [12] also stated that lower levels of spirituality were correlated with the prevalence of behavioural, psychological and mental problems including suicide, depression, and stress.

Religiosity, as part of spirituality was considered a salient component and a contributing factor to quality of life. It was recommended to be integrated in the psychotherapeutic procedures among college students [21] [22]. This was also showed by other studies, two of which were conducted in different cultures. In Kuwait, Abdel-Khalek [23] studied adolescents, middle-aged population, and college students. They found that religiosity was a principal factor for happiness 
and mental health in all age groups involved in their study. Another study in the USA by Wachholtz and Rogoff [24] found that spiritual well-being and daily spiritual experiences influence significantly the psychological status. These could also manage the rate of burnout among medical students. A study in Australia among 483 undergraduate students found that psychological status was also associated with religiosity and personal beliefs [25]. This finding gave the chance for the religious persons to be included in the team and be involved in managing the problem.

Based on the findings of this study and other related studies, one can say that psychological symptoms of students could better be managed through methods that consider spirituality as an influential factor. This approach might be beneficial for students. The introduction of spiritually-oriented materials for students in the early stages of their study might help them manage their stress and anxiety, and also improve their academic achievements [36]. This takes into consideration what was previously reported as majority of the responses of students that higher educational achievement is their top priority, which would improve job opportunity in the future, thus improve their social life and career after graduation [37].

Students' spirituality was assessed and proved positive with high scores on all items of the questionnaire. Specifically, they believed that they were equal to other people; satisfied with who they are, and have positive attitudes towards themselves [37]. Interestingly though, students reported having issues concerning their psychological wellbeing. Students' responses achieved high scores reflecting positive perception about their life, the people around them, and their environment. Students were also keen in supporting their responses. For instance, half of them stated that they try to find opportunities to enhance spirituality (49.4\%). Further, they agreed on all items related to spiritual needs, which might suggest that spirituality is part of the multidisciplinary service recommended earlier in this report. This finding suggests that either students were trying to optimize spiritual practices, or conveying positive messages about their spirituality, as well as, psychological wellbeing.

\section{Implication of the Study}

Nurses in their academic and clinical stages should have extended roles in assessing and diagnosing psychosomatic symptoms among patients, especially students in need of assistance in specialized centres. Findings from this study provided insights on the need to develop an educational program that addresses spirituality and its role in improving students' wellbeing. Further, these findings also draw the attention on the need to prepare and enable nursing educators to increase students' awareness of their psychological and spiritual needs. This can be achieved through focused and advanced education about their important role in preparing and activating the multidisciplinary service pack to assist students at their early stages. 


\section{Strengths and Weaknesses of the Study}

In addition to the large sample size of the study, a variety of measures were also considered to increase the validity of the study findings. One measure was to translate the study questionnaires to Arabic language, the mother language of the participants. This is crucial to minimize any misunderstanding of the questionnaire items and consequently provide more valid responses. Reminders were also delivered to non-respondents two weeks after questionnaires have been disseminated to increase the response rate. Further, a detailed information sheet explaining the study objectives and other pertinent details were included in the questionnaire package for participants. This package was necessary for the participants to read prior to answering the questions. It also contained the contact number of the researcher in case they have further questions for clarification.

The only limitation of the study was that participants were not equally distributed over their academic specialization with only $4.1 \%$ representing the natural sciences and $6.9 \%$ health sciences that completed the questionnaires. This requires further investigation in inviting and approaching students from other specializations, particularly nursing.

\section{Conclusion}

The prevalence of psychosomatic symptoms among university students negatively impacts on their academic achievement, as well as, their health and wellbeing in the future. This study reported that the level of spirituality influenced the psychological wellbeing of university students in South Jordan. It is therefore important to assess the presence of these symptoms as early as the adolescent stage, follow them up, and manage their symptoms using available resources within the university and the community. Although students reported the presence of psychological symptoms, they controversially reported positive assumptions about their spiritual wellbeing reflecting the need for further investigation.

\section{Acknowledgements}

The researchers wish to express their sincere thanks to Al Hussein Bin Talal University for funding the study. Special thanks to all participants and deans for their cooperation, as well as, colleagues from different colleges for their great support. Also, we wish to extend our deep appreciation for those who helped in the data collection.

\section{References}

[1] Kessler, R.C., et al. (2005) Lifetime Prevalence and Age-of-Onset Distributions of DSM-IV Disorders in the National Comorbidity Survey Replication. Archives of General Psychiatry, 62, 593-602. https://doi.org/10.1001/archpsyc.62.6.593

[2] Patel, V., et al. (2007) Mental Health of Young People: A Global Public-Health Challenge. The Lancet, 369, 1302-1313. https://doi.org/10.1016/S0140-6736(07)60368-7

[3] Lindström, M., Fridh, M. and Rosvall, M. (2014) Economic Stress in Childhood and 
Adulthood, and Poor Psychological Health: Three Life Course Hypotheses. Psychiatry Research, 215, 386-393. https://doi.org/10.1016/j.psychres.2013.11.018

[4] Weich, S., et al. (2011) Mental Well-Being and Mental Illness: Findings from the Adult Psychiatric Morbidity Survey for England 2007. The British Journal of Psychiatry, 199, 23-28. https://doi.org/10.1192/bjp.bp.111.091496

[5] Por, J., et al. (2011) Emotional Intelligence: Its Relationship to Stress, Coping, Well-Being and Professional Performance in Nursing Students. Nurse Education Today, 31, 855-860. https://doi.org/10.1016/j.nedt.2010.12.023

[6] Dyrbye, L.N., Thomas, M.R. and Shanafelt, T.D. (2006) Systematic Review of Depression, Anxiety, and Other Indicators of Psychological Distress among US and Canadian Medical Students. Academic Medicine, 81, 354-373. https://doi.org/10.1097/00001888-200604000-00009

[7] Saipanish, R. (2003) Stress among Medical Students in a Thai Medical School. Medical Teacher, 25, 502-506. https://doi.org/10.1080/0142159031000136716

[8] Sherina, M., Rampal, L. and Kaneson, N. (2004) Psychological Stress among Undergraduate Medical Students. Medical Journal of Malaysia, 59, 207-211.

[9] Baetz, M. and Toews, J. (2009) Clinical Implications of Research on Religion, Spirituality, and Mental Health. The Canadian Journal of Psychiatry, 54, 292-301. https://doi.org/10.1177/070674370905400503

[10] Verghese, A. (2008) Spirituality and Mental Health. Indian Journal of Psychiatry, 50, 233. https://doi.org/10.4103/0019-5545.44742

[11] Johnstone, B., et al. (2012) Relationships among Spirituality, Religious Practices, Personality Factors, and Health for Five Different Faith Traditions. Journal of Religion and Health, 51, 1017-1041. https://doi.org/10.1007/s10943-012-9615-8

[12] Powell, L.H., Shahabi, L. and Thoresen, C.E. (2003) Religion and Spirituality: Linkages to Physical Health. American Psychologist, 58, 36. https://doi.org/10.1037/0003-066X.58.1.36

[13] Benson, P.L., Roehlkepartain, E.C. and Rude, S.P. (2003) Spiritual Development in Childhood and Adolescence: Toward a Field of Inquiry. Applied Developmental Science, 7, 205-213. https://doi.org/10.1207/S1532480XADS0703_12

[14] Creel, E. and Tillman, K. (2008) The Meaning of Spirituality among Nonreligious Persons with Chronic Illness. Holistic Nursing Practice, 22,303-309. https://doi.org/10.1097/01.HNP.0000339340.96005.ff

[15] Spilka, B., et al. (2003) The Psychology of Religion: An Empirical Approach. Guilford Press, New York.

[16] Deb, S., McGirr, K. and Sun, J. (2016) Spirituality in Indian University Students and Its Associations with Socioeconomic Status, Religious Background, Social Support, and Mental Health. Journal of Religion and Health, 55, 1623-1641. https://doi.org/10.1007/s10943-016-0207-x

[17] Yamashita, K., Saito, M. and Takao, T. (2012) Stress and Coping Styles in Japanese Nursing Students. International Journal of Nursing Practice, 18, 489-496.

[18] Kash, K.M., et al. (2000) Stress and Burnout in Oncology. Oncology, 14, 1621-1633.

[19] Holland, J.M. and Neimeyer, R.A. (2005) Reducing the Risk of Burnout in End-of-Life Care Settings: The Role of Daily Spiritual Experiences and Training. Palliative \& Supportive Care, 3, 173-181. https://doi.org/10.1017/S1478951505050297

[20] Vasegh, S. and Mohammadi, M.R. (2007) Religiosity, Anxiety, and Depression among a Sample of Iranian Medical Students. International Journal of Psychiatry in 
Medicine, 37, 213-227. https://doi.org/10.2190/J3V5-L316-0U13-7000

[21] Abdel-Khalek, A.M. (2010) Quality of Life, Subjective Well-Being, and Religiosity in Muslim College Students. Quality Of Life Research: An International Journal of Quality of Life Aspects of Treatment, Care and Rehabilitation, 19, 1133-1143. https://doi.org/10.1007/s11136-010-9676-7

[22] Zullig, K.J., Ward, R.M. and Horn, T. (2006) The Association between Perceived Spirituality, Religiosity, and Life Satisfaction: The Mediating Role of Self-Rated Health. Social Indicators Research, 79, 255-274. https://doi.org/10.1007/s11205-005-4127-5

[23] Abdel-Khalek, A.M. (2012) Subjective Well-Being and Religiosity: A Cross-Sectional Study with Adolescents, Young and Middle-Age Adults. Mental Health, Religion \& Culture, 15, 39-52. https://doi.org/10.1080/13674676.2010.551324

[24] Wachholtz, A. and Rogoff, M. (2013) The Relationship between Spirituality and Burnout among Medical Students. Journal of Contemporary Medical Education, 1, 83-91. https://doi.org/10.5455/jcme.20130104060612

[25] Lopez, V., et al. (2014) Spirituality, Religiosity, and Personal Beliefs of Australian Undergraduate Nursing Students. Journal of Transcultural Nursing. Official Journal of the Transcultural Nursing Society, 25, 395-402. https://doi.org/10.1177/1043659614523469

[26] Daradkeh, T., et al. (2006) Psychiatric Morbidity and Its Sociodemographic Correlates among Women in Irbid, Jordan.

[27] Abu-Ghazaleh, S.B., Rajab, L.D. and Sonbol, H.N. (2011) Psychological Stress among Dental Students at the University of Jordan. Journal of Dental Education, 75, 1107-1114.

[28] Al-Jaddou, H. and Malkawi, A. (1997) Prevalence, Recognition and Management of Mental Disorders in Primary Health Care in Northern Jordan. Acta Psychiatrica Scandinavica, 96, 31-35. https://doi.org/10.1111/j.1600-0447.1997.tb09901.x

[29] Goldberg, D.P., et al. (1997) The Validity of Two Versions of the GHQ in the WHO Study of Mental Illness in General Health Care. Psychological Medicine, 27, 191-197. https://doi.org/10.1017/S0033291796004242

[30] Parsian, N. and Dunning, T. (2009) Spirituality and Coping in Young Adults with Diabetes: A Cross-Sectional Study. European Diabetes Nursing, 6, 100-104. https://doi.org/10.1002/edn.144

[31] Padron, A.M.D., Galan, I.P. and Rodriguez-Artalejo, F.P. (2012) Behavioral Risk Factors and Mental Health: Single and Cluster Associations in Spanish Adolescents. Journal of Developmental \& Behavioral Pediatrics, 33, 698-704. https://doi.org/10.1097/DBP.0b013e31826ba9d9

[32] Patton, G.C., et al. (2014) The Prognosis of Common Mental Disorders in Adolescents: A 14-Year Prospective Cohort Study. The Lancet, 383, 1404-1411. https://doi.org/10.1016/S0140-6736(13)62116-9

[33] Boot, C.R., et al. (2009) Development of a Student Health Questionnaire: The Necessity of a Symbiosis of Science and Practice. Global Health Promotion, 16, 35-44. https://doi.org/10.1177/1757975909339763

[34] Bertelli, M.O., et al. (2015) Diagnosing Psychiatric Disorders in People with Intellectual Disabilities: Issues and Achievements. Advances in Mental Health \& Intellectual Disabilities, 9, 230-242. https://doi.org/10.1108/AMHID-05-2015-0023

[35] Koenig, H.G. (2009) Research on Religion, Spirituality, and Mental Health: A Review. The Canadian Journal of Psychiatry, 54, 283-291. 
https://doi.org/10.1177/070674370905400502

[36] Trockel, M.T., Barnes, M.D. and Egget, D.L. (2000) Health-Related Variables and Academic Performance among First-Year College Students: Implications for Sleep and Other Behaviors. Journal of American College Health, 49, 125-131. https://doi.org/10.1080/07448480009596294

[37] Boro, J. and Dhanalakshmi, D. (2015) Spirituality, Personality and General Health among College Students. Indian Journal of Health and Wellbeing, 6, 475-479. 